\title{
Diaphragm disease: pathology of disease of the small intestine induced by non-steroidal anti-inflammatory
} drugs

\author{
J LANG,* A B PRICE, * A J LEVI, $\dagger$ M BURKE,§ J M GUMPEL, $\ddagger$ I BJARNASON $\dagger$ \\ From the Departments of *Histopathology, †Gastroenterology, $\ddagger$ Rheumatology, and §Surgery, Northwick Park \\ Hospital and Clinical Research Centre, Harrow, Middlesex
}

SUMMARY Operative small bowel resection specimens received over a period of 16 years were reviewed to assess whether any intestinal disease could be directly attributed to the use of nonsteroidal anti-inflammatory drugs (NSAID). Seven cases of intestinal disease associated with the use of NSAID were identified, all of which occurred in the final six years of the survey, which may reflect the increasing use of these compounds. A spectrum of patterns was found from multiple pathognomonic ileal mucosal diaphragms to broad strictures similar to those seen as a complication of enteric potassium. It seems likely that the formation of diaphragm lesions requires an additional factor, but what is not known as yet is whether the effects of NSAID are local or systemic.

Several non-steroidal anti-inflammatory drugs (NSAID) cause characteristic small bowel lesions in animals. This is most severe in rats in which indomethacin leads to multiple small bowel ulcers, mainly in the ileum. ${ }^{2}$ The ulcers often perforate, with consequent peritonitis, and death may result after as little as a single subcutaneous dose of $10 \mathrm{mg} / \mathrm{kg}$. The pathogenesis of these lesions is incompletely understood, but they can be prevented by treatment with prostaglandins and antibiotics. One hypothesis, therefore, is that a reduction in the mucosal synthesis of prostaglandins induced by non-steroidal anti-inflammatory drugs disrupts mucosal integrity and the subsequent ulceration might then reflect bacterial invasion..$^{3-5}$

Indirect evidence suggests that a similar process may occur in man. We have shown that NSAID swiftly disrupt small intestinal integrity in normal subjects assessed by a ${ }^{51}$ chromium labelled ethylenediaminetetra-acetate ( ${ }^{51}$ EDTA) absorption test, and the damage, which is likely to affect the intercellular junctions between enterocytes, seems to be proportional to the drugs' ability to inhibit cyclo-oxygenase. Furthermore, it is clear that long term treatment with NSAID in patients with rheumatoid and osteoarthritis is associated with distinct migratory abnormalities of "indium-labelled leucocytes. Although these collect in the right iliac fossa, analysis of the kinetics of "'indium leucocyte accumulation suggests that the Accepted for publication 8 December 1987 whole of the small intestine may be inflamed..$^{6-8} \mathrm{~A}$ four day estimation of faecal "'indium activity, which is a reliable objective index of intestinal inflammation, is abnormal in treated patients, while untreated ones invariably have normal results. There is now accumulating epidemiological and experimental data to show that NSAID are associated with a clinically important gastrointestinal blood and protein loss. ${ }^{9}$ The ileal dysfunction and sporadic reports of perforation suggest that small intestinal inflammation associated with the use of NSAID is, in fact, a new nosological entity..$^{1011}$

Histopathological confirmation of intestinal inflammation complementing these investigations is, however, scarce. These are accounts of potassium preparations causing small bowel ulceration, but many of these patients were also receiving NSAID. ${ }^{12}$ There are also reports of small intestinal ulceration, perforations, and strictures induced by NSAID. ${ }^{13-15}$ Our purpose was to review operative small bowel resection specimens received by the department of histopathology at Northwick Park Hospital over 16 years and to assess whether any intestinal disease could be identified, implicating NSAID as the cause of the pathology.

The picture that emerged, as far as we are aware, seems to be unique to small intestinal pathology associated with NSAID, and we have termed this "diaphragm disease". 


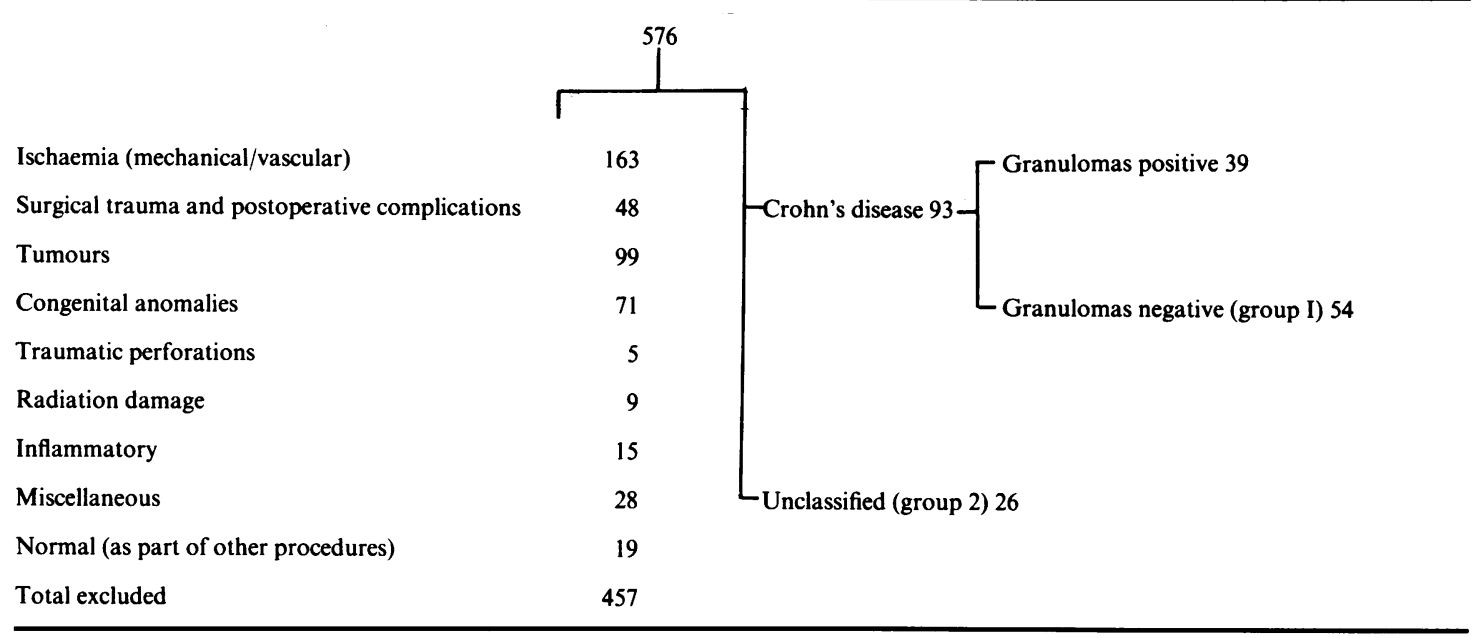

\section{Material and methods}

Between January 1971 and March 1987, 576 small bowel resections were examined in the department of histopathology at Northwick Park Hospital. The pathology reports of these cases were reviewed and those with clinical details and histological descriptions denoting a confident diagnosis of ischaemia, neoplasia, operative complications, infections, congenital anomalies and certain miscellaneous conditions, but with pathognomonic histopathology, were excluded from further assessment (table 1). This accounted for 457 cases.

One hundred and nineteen cases remained, compris- ing 93 diagnosed as Crohn's disease and an unclassified group of 26 (table 1). Study of the reports of the patients with Crohn's disease identified 39 with granulomas and 54 without. Where granulomas were noted the diagnosis of Crohn's disease was accepted and the slides and clinical history were not reviewed.

Primary pathology due to NSAID was assumed to lie within the group of 54 cases of Crohn's disease without granulomas (group 1) and the 26 cases (group 2 ) that were unclassified. The clinical records and histological sections of these two groups were reviewed in detail. Group 2 (unclassified) required division into subgroups to encompass the range of pathologies.

Table 2 Group 2: 26 unclassified cases

\begin{tabular}{|c|c|c|c|c|c|}
\hline \multirow{2}{*}{ Subgroup } & \multirow{2}{*}{$\begin{array}{l}\text { No of } \\
\text { cases }\end{array}$} & \multicolumn{2}{|l|}{ Predominant pathology } & \multirow[b]{2}{*}{ Drug } & \multirow[b]{2}{*}{ Final diagnosis } \\
\hline & & Macroscopic & Microscopic & & \\
\hline $\bar{A}$ & 7 & Multiple mucosal diaphragms & Focal submucosal fibrosis & NSAID & Iatrogenic strictures \\
\hline \multirow[t]{2}{*}{ B } & 5 & $\begin{array}{l}\text { Single/multiple short } \\
\text { strictures }\end{array}$ & Diffuse submucosal fibrosis & & 2 Crohn's disease, \\
\hline & & & & Phenylbutazone & $\begin{array}{l}1 \text { Healed tuberculosis } \\
1 \text { Recurrent hernia } \\
1 \text { Iatrogenic stricture }\end{array}$ \\
\hline C & 4 & Perforation & Acute inflammation & & Perforation ? cause \\
\hline D & 4 & $\begin{array}{l}\text { Short strictures and } \\
\text { ulceration }\end{array}$ & Apthoid ulcers, transmural inflammation & & $\begin{array}{l}\text { Probable Crohn's } \\
\text { disease }\end{array}$ \\
\hline E & 2 & Hour glass deformity & Full thickness inflammatory ulcers & Potassium & $\begin{array}{l}1 \text { Iatrogenic stricture } \\
1 \text { ? Coeliac disease }\end{array}$ \\
\hline $\mathbf{F}$ & 2 & Focal areas of necrosis & & & Ischaemia \\
\hline G & 1 & Oedema & Intense mucosal and submucosal inflammation & & ? Infection \\
\hline $\mathbf{H}$ & 1 & Thick mucosa & Extensive villous regenerative/dysplastic changes & & No diagnosis made \\
\hline
\end{tabular}




\section{Results}

GROUP 1

This group had been indexed Crohn's disease in the absence of granulomas. On review all the cases had sufficient pathological attributes for this diagnosis to be accepted. ${ }^{16}$ In particular, all showed a combination of transmural inflammation, mostly as aggregates of lymphocytes, and fissuring ulceration. The clinical and radiological data supported the diagnosis. Two of this group had clearly received NSAID before developing Crohn's disease, but in many cases the drug history was inadequately documented at presentation.

\section{GROUP 2}

This group comprised 26 small bowel resections without a confident diagnostic label. After review of the macroscopic data (accompanied by photographs in many cases) the histology and the clinical histories of these could be assigned to several broad subgroups (table 2). The drug history was then added and an attempt at a diagnostic conclusion was made. In some cases this final diagnosis was made easier by access to follow up data not available at the time of resection. Table 2 shows that seven cases (group 2A) presented a striking macroscopic picture with characteristic histology which was accompanied by a convincing history of recent ingestion of NSAID. Two of these seven cases had been referred from other hospitals for a pathological opinion because of their unusual features. From among the other subgroups in table 2 group 2B comprised five with strictures predominantly due to submucosal fibrosis. In this respect there was some similarity with the group 2A NSAID group (see below). One of this group had received NSAID. Two more patients from other groups had regularly taken a drug with recognised gastrointestinal side effects, but no others were receiving NSAID.

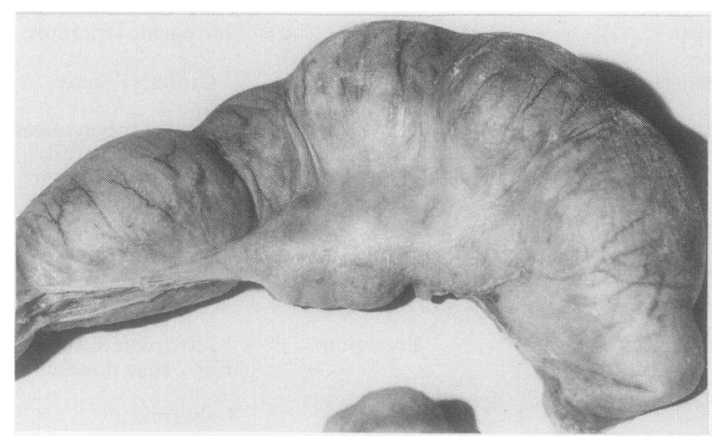

Fig 1 Bland serosal aspect of resected ileum (case 3) emphasises how difficult it is for surgeons to appreciate the lesions seen (fig 2) before the bowel is opened.
GROUP 2A

The macroscopic features in the five cases resected at Northwick Park Hospital were similar and dramatic. The resections were lengths of ileum from $14 \mathrm{~cm}$ to 80 $\mathrm{cm}$ which never included the terminal ileum. There was mild or moderate dilatation of the bowel and thickening of what, from the serosal aspect, were assumed to be mucosal folds (fig 1).

This relatively bland external appearance contrasted with the mucosal aspect. The lumen of the ileum in all cases was divided into compartments by multiple thin circumferential mucosal membranes (fig 2). The features were clearly seen because of formalin inflation of the specimens prior to opening. Each resembled the washer of a tap or a perforated diaphragm. The luminal orifices of these divisions varied from 3-4 mm to a width only a little less than the full intestinal diameter (figs $3 \mathrm{a}$ and $\mathrm{b}$ ). At the latter sites they appeared as little more than exaggerated plicae circulares but were circumferential and had a slightly broader base. The distribution of these diaphragm lesions along the lengths of resected ileum was uneven, varying from every $2-3 \mathrm{~cm}$ to up to $10-15 \mathrm{~cm}$. In the longest resected specimen of $70 \mathrm{~cm} 19$ were present along its length. In this instance the surgeon had already carried out a large number of stricturoplasties at an initial laparotomy (table 3). Pinpoint ulceration could be seen around the luminal margins of the diaphragms in some specimens. Within the intestinal compartments formed by these diaphragms focal haemorrhagic roughened areas and occasional tiny ulcers were present but the bulk of the mucosa appeared normal. The macroscopic description of cases 6 and 7, the two referred cases (table 3) was of

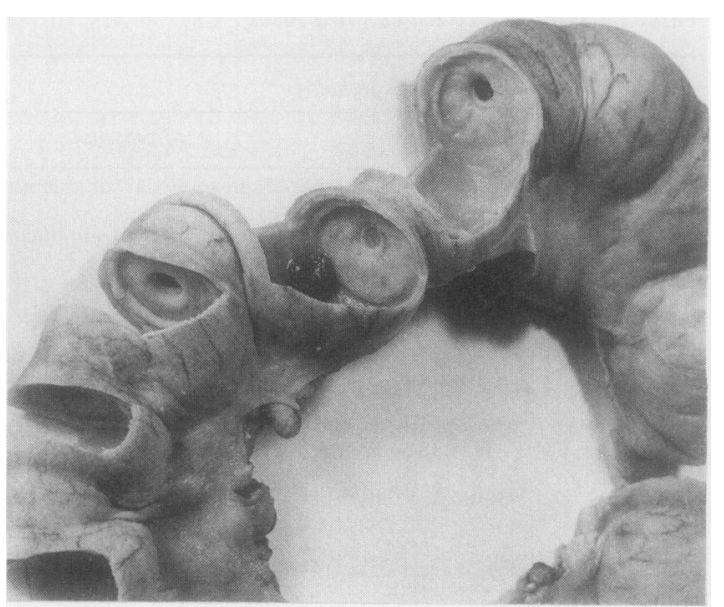

Fig 2 Resected length of ileum shows multiple mucosal diaphragms (case 2). One tablet (not an NSAID) was found within one compartment. 


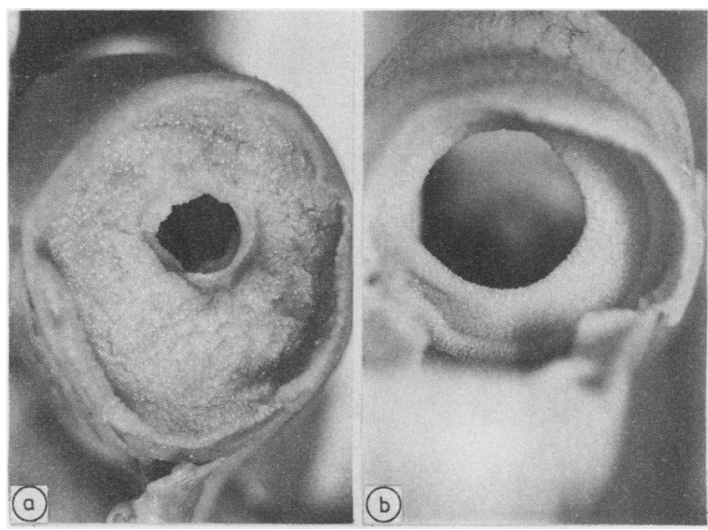

Fig 3 (a) Direct view of mucosal diaphragms illustrate variation in width of luminal apertures; (b) appearances differ little from prominent plicae circulares.

multiple thickened ridges along the resected lengths of ileum.

Crohn's disease was the favoured initial medical and surgical diagnosis in the earlier cases but more recently clinicians, aware of the condition, have suspected the diagnosis prior to laparotomy. One patient, case 4 (table 3), had received previous radiotherapy and a stricture caused by radiation was thought likely. On the basis of recurrent obstruction four of the six cases required two resections: in case 7 (table 3 ) these were eight years apart.

\section{MICROSCOPY}

The main histological findings were limited to the vicinity of the macroscopic changes and the occasional small focal lesions noted within dilated bowel segments. Two slightly different patterns were seen but both were characterised by the pattern of fibrosis in the superficial half of the submucosa immediately beneath the muscularis. The first pattern related to the thin occluding mucosal diaphragms, the second to the broader based ridges with less luminal occlusion.

\section{MUCOSAL DIAPHRAGMS}

Each had the basic structure of the normal plicae circulares-that is, a thin fold of mucosa, muscularis mucosae, and submucosa. No muscularis propria was affected. Characteristic and present in all the "diaphragmatic" lesions examined was a focus of submucosal fibrosis. This was best appreciated at low powers of magnification, which emphasised the directional symmetry of collagen bundles aligned towards the apex of the lesion (figs 4 and 5). The muscularis mucosae appeared to break up and merge with this underlying fibrosis. In some it was only the condensation of collagen bundles seen beneath the muscularis, together with minor overlying mucosal inflammation and villous irregularity that helped distinguish the lesions from normal plicae circulares (figs 5 and 6).

The mucosa at the apex was mildly but invariably inflamed, with or without shallow ulceration. This was

Table 3 Clinical details of patients with small bowel disease induced by NSAID

\begin{tabular}{|c|c|c|c|c|c|}
\hline $\begin{array}{l}\text { Case } \\
\text { No }\end{array}$ & Age & Clinical features & Drugs & Surgery & Outcome \\
\hline 1 & 70 & $\begin{array}{l}\text { Osteoarthritis } 2 \text { years } \\
\text { Anaemia } \\
\text { Subacute obstruction }\end{array}$ & Piroxicam (18 months) & $\begin{array}{l}2 \text { resections } \\
4 \text { weeks apart } \\
70 \mathrm{~cm} \text { and } 30 \mathrm{~cm} \text { of } \\
\text { proximal, and mid- } \\
\text { ileum }\end{array}$ & Well \\
\hline $2 *$ & 71 & $\begin{array}{l}\text { Seropositive rheumatoid arthritis } \\
28 \text { years } \\
\text { Anaemia } \\
\text { Subacute obstruction }\end{array}$ & $\begin{array}{l}\text { Long acting indomethacin; various others } \\
\text { over } 16 \text { years }\end{array}$ & $\begin{array}{l}2 \text { resections } \\
6 \text { months apart } 27 \mathrm{~cm} \\
\text { and } 14 \mathrm{~cm} \text { of } \\
\text { proximal ileum }\end{array}$ & $\begin{array}{l}\text { Died from post- } \\
\text { operative } \\
\text { complications }\end{array}$ \\
\hline $3^{*}$ & 40 & $\begin{array}{l}\text { Seropositive rheumatoid arthritis } \\
30 \text { years } \\
\text { Anaemia } \\
\text { Subacute obstruction }\end{array}$ & $\begin{array}{l}\text { Azapropazone } 3 \text { years; aspirin and various } \\
\text { others in past }\end{array}$ & $\begin{array}{l}1 \text { resection } 50 \mathrm{~cm} \text { mid- } \\
\text { ileum }\end{array}$ & Well \\
\hline 4 & 75 & $\begin{array}{l}\text { Osteoarthritis } 15 \text { years } \\
\text { Subacute obstruction } \\
\text { Breast and cervical cancer } \\
\text { Radiotherapy }\end{array}$ & $\begin{array}{l}\text { Piroxicam } \\
\text { Ketoprofen } \\
\text { Brufen }\end{array}$ & $\begin{array}{l}1 \text { resection } \\
20 \mathrm{~cm} \text { mid-ileum }\end{array}$ & $\begin{array}{l}\text { Probable additional } \\
\text { radiation damage }\end{array}$ \\
\hline $5^{*}$ & 64 & $\begin{array}{l}\text { Seropositive rheumatoid arthritis } \\
15 \text { years } \\
\text { Subacute obstruction }\end{array}$ & Piroxicam 3 years & $\begin{array}{l}1 \text { resection } \\
15 \mathrm{~cm} \text { distal ileum } \\
15 \mathrm{~cm} \text { distal ileum }\end{array}$ & Well \\
\hline 6 & 72 & Osteoarthritis? years & Piroxicam 5 years and various others & $\begin{array}{l}1 \text { resection } 5 \mathrm{~cm} \text { distal } \\
\text { ileum }\end{array}$ & $?$ \\
\hline 7 & 78 & Osteoarthritis many years & Wide variety but no details available & $\begin{array}{l}2 \text { resections, } 8 \text { years } \\
\text { apart, } 7 \mathrm{~cm} \text { and } \\
14 \mathrm{~cm} \text { mid-ileum }\end{array}$ & $?$ \\
\hline
\end{tabular}

*These patients were also receiving disease modifying drugs such as gold, penicillamine, salazopyrine 


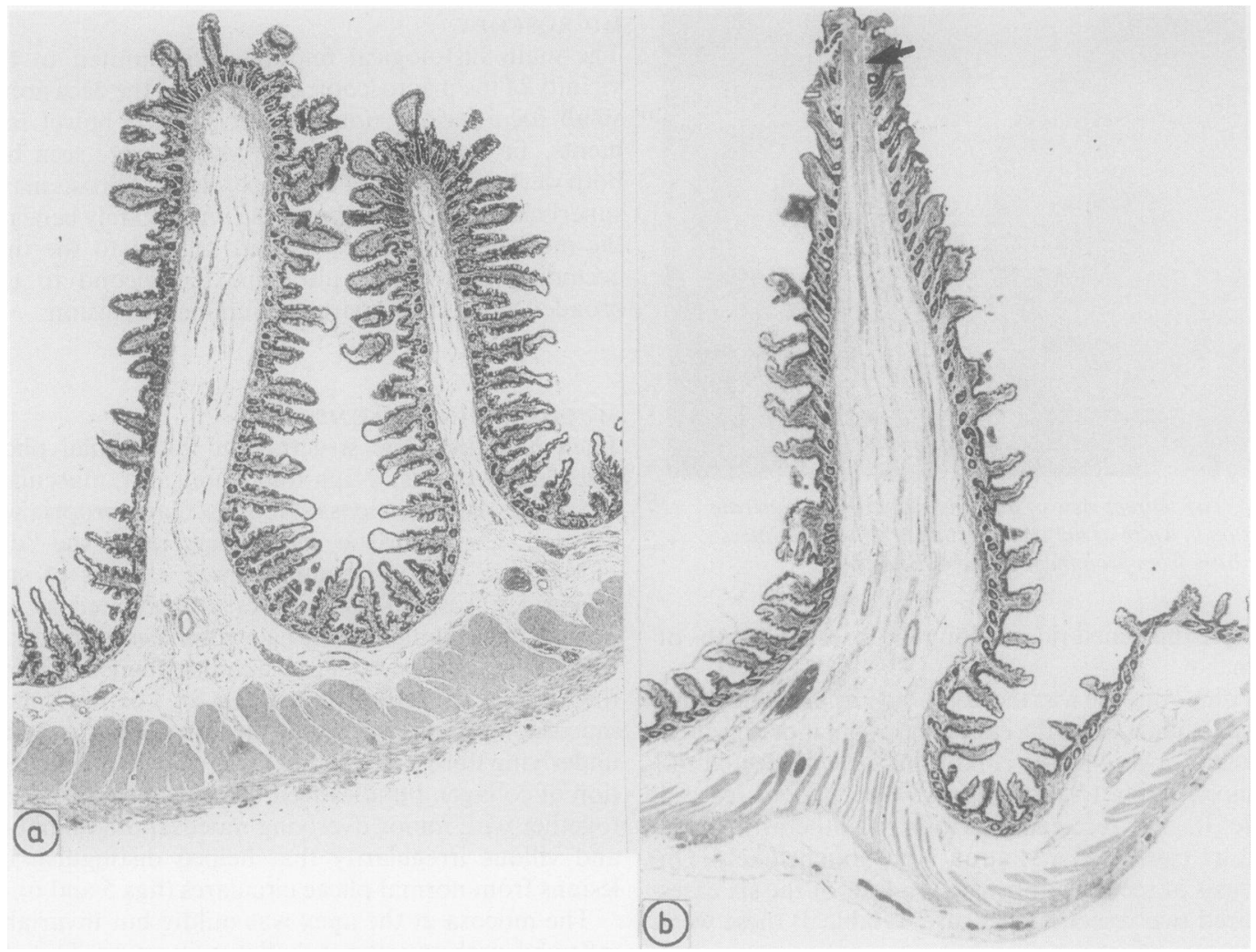

Fig 4 (a) Normal plicae circulares are seen left and right (b) a cross section of mucosal diaphragm caused by NSAID. Distinction is made by observing submucosal fibrosis in diaphragm lesion (arrowed). (Haematoxylin and eosin.)

accompanied by degrees of villous atrophy for a short distance on either side. The epithelium was hyperplastic, the enterocytes being basophilic with increased numbers of mitoses. Goblet cells were diminished. Neutrophil polymorphs, eosinophils, lymphocytes and plasma cells were increased in the abnormal mucosal areas and this was most intense at the apices of the lesions. The degree of ulceration varied from surface epithelial erosions to full thickness mucosal loss. The inflammation and villous abnormality diminished gradually with progression towards the base of the diaphragm.

\section{Broad based stenoses}

With increasing amounts of submucosal fibrosis the cross section of the lesions broadened to become hump-shaped. Macroscopically this pattern corresponded to those areas with less luminal occlusion and with the macroscopic descriptions of ridges as in cases 6 and 7 (table 3). The submucosal fibrosis was dome- shaped, and the upper collagen bundles merged with the muscularis mucosae but the base was usually separate from the muscularis propria (fig 7). The mucosal changes were similar to those within the diaphragms, but ulceration, when present, was more prominent.

\section{Accompanying mucosal abnormalities}

The mucosa within the ileal compartments between the diaphragms and ridges was for the most part entirely normal. There were occasional focal areas of moderate partial villous atrophy with a patchy minor increase in inflammatory cells in which eosinophils were prominent. Occasional ulcers were seen in flat mucosa with a basic pattern similar to those noted on the diaphragms (fig 8). The resection from case 4 who had received previous radiotherapy (table 3 ) showed widespread collagen and vascular damage typical of radiation, in addition to the pathology already described. 


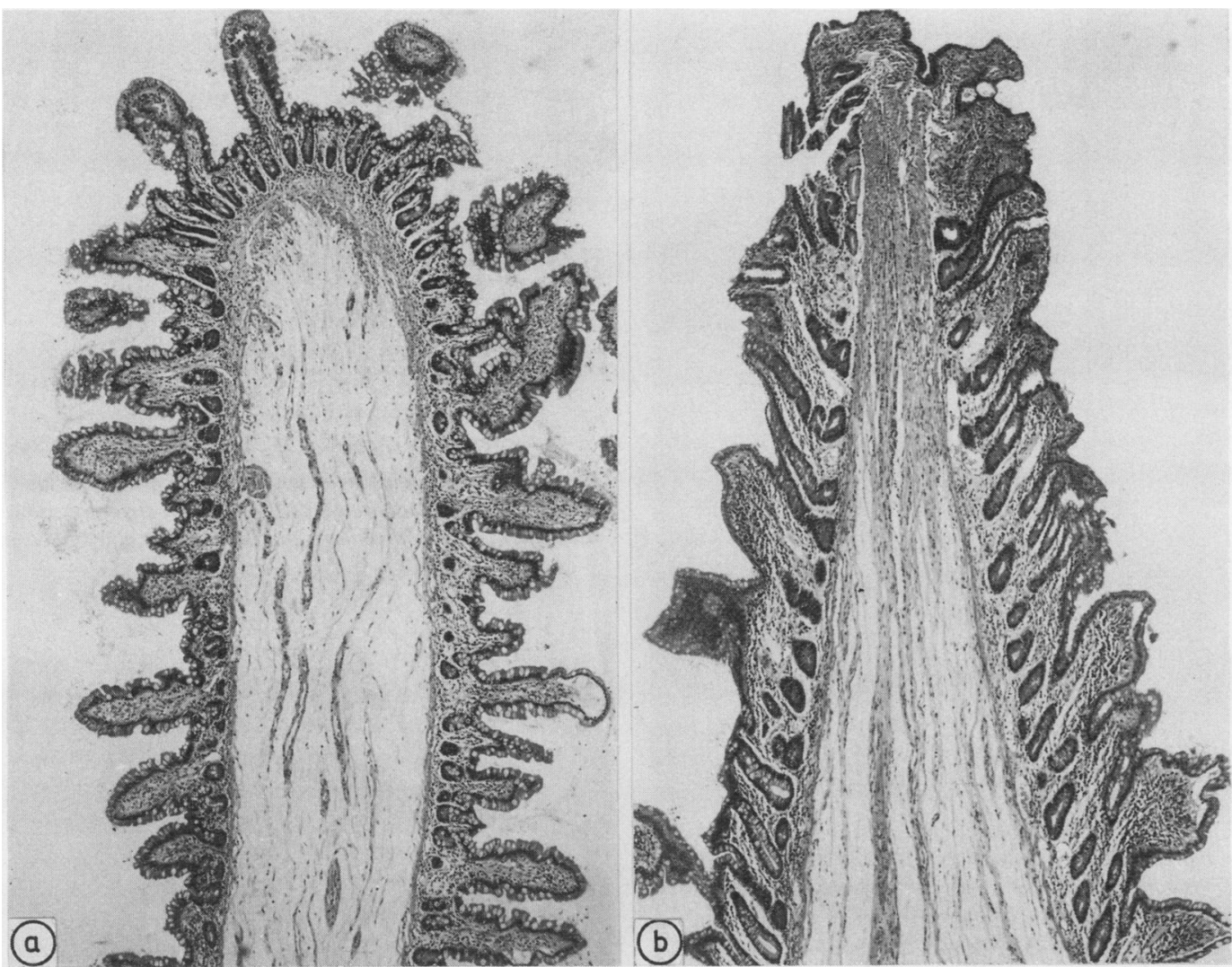

Fig 5 Higher power illustration of fig 4 to emphasise intact muscularis mucosae in normal plicae circulares (a) and submucosal fibrotic focus at apex of diaphragm (b). (Haematoxylin and eosin.)

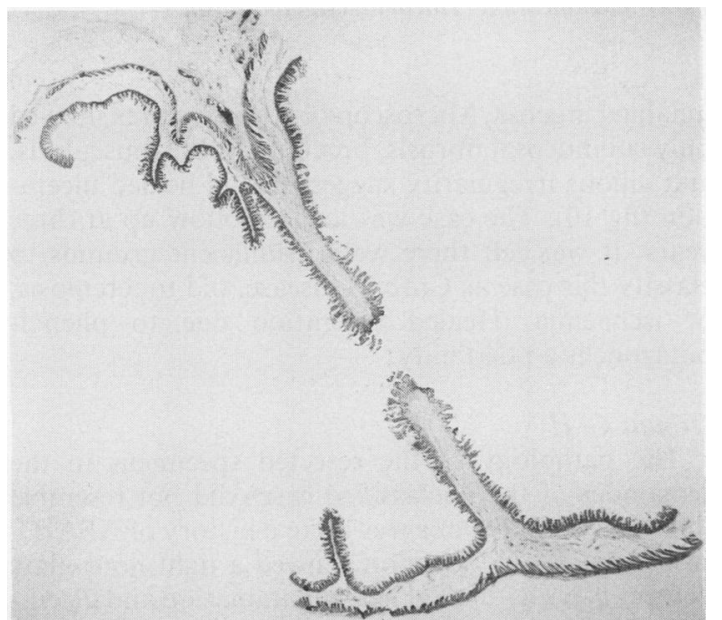

Fig 6 Complete cross section of diaphragm through its aperture. Plicae are seen to one side. (Haematoxylin and eosin.)

\section{PATHOLOGY OF OTHER GROUPS}

Group $2 B$

Assembled here are five cases with submucosal fibrosis as the main microscopic finding, associated with some overlying mucosal villous distortion that suggested previous damage. There were no other histological clues to permit a confident diagnostic classification at the time of resection: only one had received NSAID. The macroscopic pathology in all five was different from that described above. The strictures were at least $2-3 \mathrm{~cm}$ in length and never exceeded two in number. Nothing resembling the diaphragm lesions was seen.

On review, and with the benefit of clinical and in some cases biopsy follow up data, two cases were reclassified as Crohn's disease. One case, in view of the history, was accepted as old tuberculosis, and the changes in another were assumed related to the affected intestine being caught recurrently in a hernial sac (fig 9).

The final case in this group is of interest, but the 


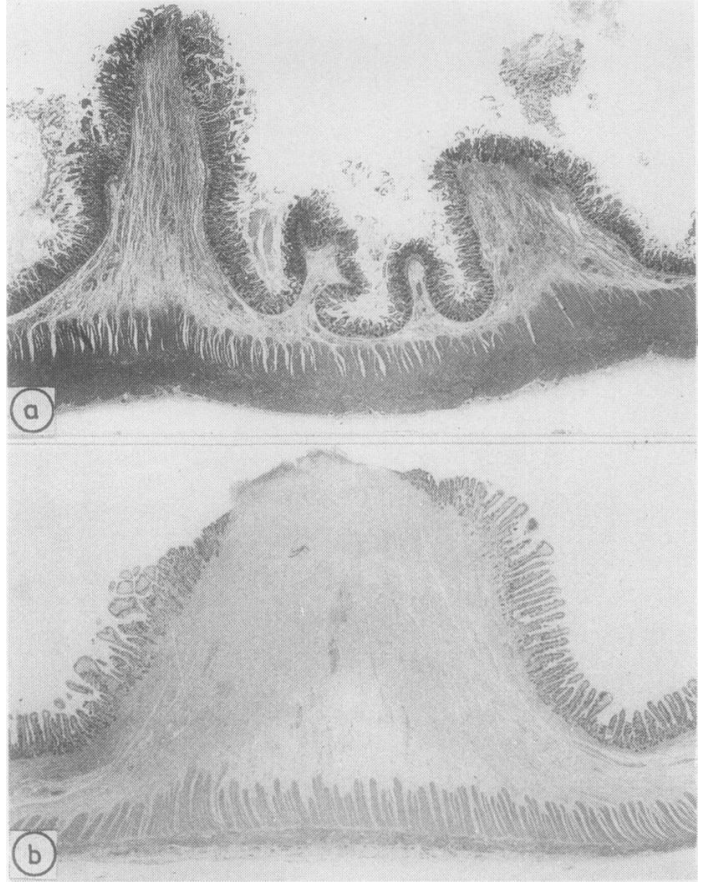

Fig 7 Ridge or humped pattern of lesion seen in several cases, but particularly cases $6(a)$ and $7(b)$. Submucosal fibrosis is conspicuous, but a gap is seen between it and the muscularis propia. Note complete absence of any mural inflammation and localised nature of deformity. There is a pronounced difference in the degree of ulceration between the two lesions. (Haematoxylin and eosin.)

diagnosis remains equivocal. There was a long history of phenylbutazone administration for lower back pain. An equivocal diagnosis of ankylosing spondylitis was lacking. The resected specimen contained two short flat ileal strictures separated by $10 \mathrm{~cm}$ of mildly

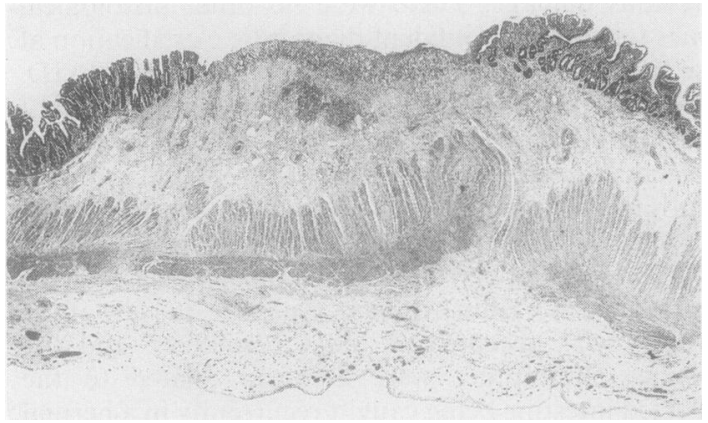

Fig 8 Ulceration and fibrosis in flat mucosa, an occasional finding. (Haematoxylin and eosin.)

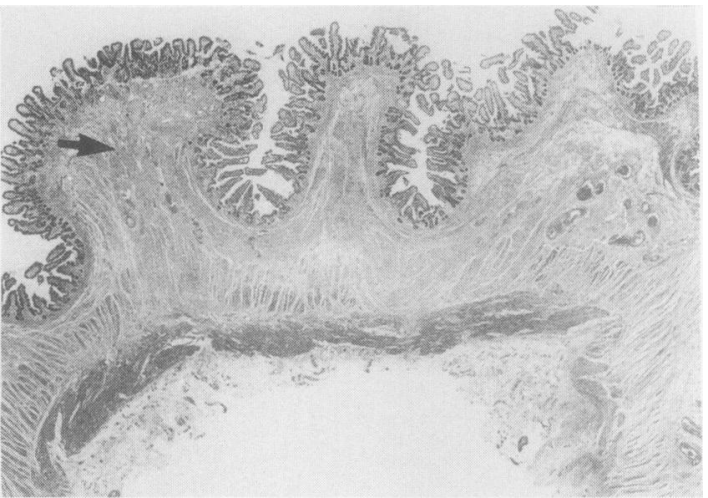

Fig 9 Resected ileum from patient in group $2 b$ showing submucosal fibrosis (arrowed) producing a stricture. Bowel was caught in a recurrent hernia. (Haematoxylin and eosin.)

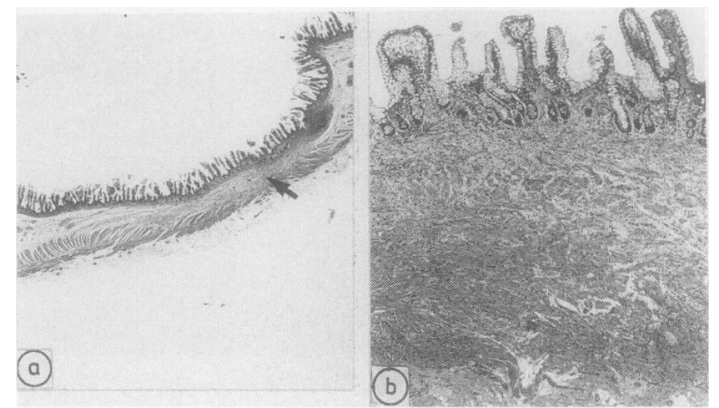

Fig 10 (a) Resected ileum from the patient in group $2 b$ who had received phenylbutazone. A stricture (arrowed) is seen towards the right margin; (b) strictured area seen at higher magnification (Haematoxylin and eosin.)

inflamed mucosa. Microscopy of the strictures showed only submucosal fibrosis, break up of the muscularis, and villous irregularity suggesting old healed ulceration (fig 10). The case was lost to follow up at three years. It was felt there were insufficient grounds to classify this case as Crohn's disease, old tuberculosis, or ischaemia. Healed ulceration due to phenylbutazone is a possibility.

\section{Groups $C-H$}

The pathology of the resected specimens in the remainder of the unclassified cases did not resemble those in group $2 \mathrm{~A}$, nor was there a history of NSAID. In group $2 \mathrm{E}$ one resection showed a tight hour-glass deformity with full thickness inflammation and ulceration. The patient had been receiving potassium supplements. While interesting, these remaining cases are beyond the scope of this study. 


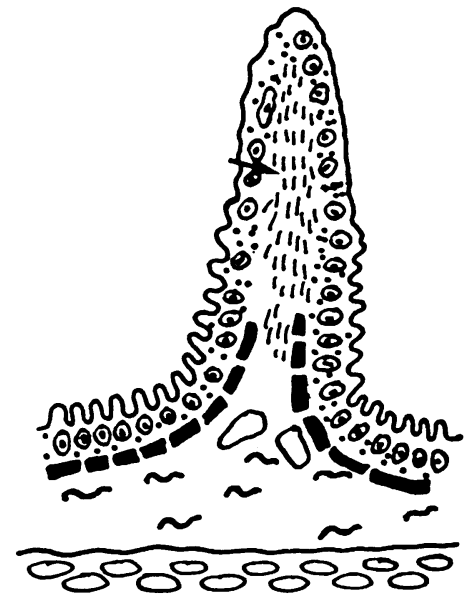

(a)

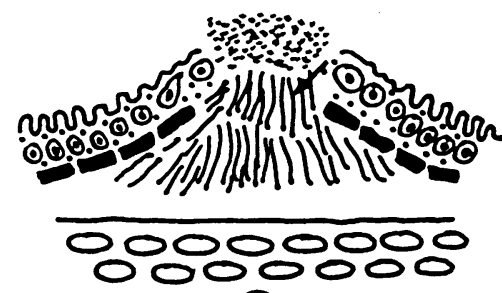

(b)

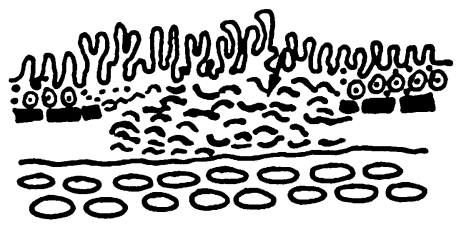

(c)

Fig 11 Possible evolution of mucosal and submucosal changes seen after NSAID (a) thin mucosal diaphragm which by progressive submucosal fibrosis (arrows) broadens to $b$ and ultimately to a flat stricture $c$.

\section{Discussion}

This investigation identified a small group of patients taking NSAID who develop what seems to be a pathognomonic macroscopic picture of ileal disease accompanied by typical, though probably not specific, histological changes. The pattern was of segmentation mainly of the mid-ileum brought about by the formation of incomplete diaphragms of mucosa. At one extreme, they appeared as grossly exaggerated plicae circulares reducing the lumen to a few millimetres (figs 4-6): at the other, the mucosal and submucosal abnormalities were blunter forming a ridge or hump (fig 7). There was often circumferential ulceration. The length of the bowel compartment formed varied from 3-4 $\mathrm{cm}$ up to $10-15 \mathrm{~cm}$. The dramatic mucosal aspect contrasted sharply with a misleadingly bland appearance seen by the surgeon at laparotomy (figs 1 and 2).

The important histological features relate to the different gross appearances of the thin diaphragms and the broader based lesions. What was striking and the best clue to the diagnosis in both, was the pattern of submucosal fibrosis. In the thin diaphragms it was limited to a tiny submucosal focus at the luminal border (fig 5 b) but became dome-shaped in the lesions with a broader base (fig 7). In the thinnest lesions the collagen bundles were aligned at right angles to the mucosa (figs 4 and 5). It is this fibrosis that distinguishes these very thin diaphragms from plicae circulares. The mucosa, when ulcerated, remained flat or slightly raised rather than excavated. This also applied to the occasional ulcerative foci in flat areas of mucosa (fig 8 ). The inflammatory changes and villous distortion accompanying the lesion seemed to be secondary and non-specific.

\section{DIFFERENTIAL DIAGNOSIS}

The multiple thin diaphragms produced a pattern that, at the time of writing, seemed a unique complication of NSAID ingestion. The broader based stenoses, although also highly suggestive, cannot be considered to be specific, and open up several diagnoses for the pathologist and clinician to consider. For example, they conform more to the pattern of iatrogenic strictures and ulceration described by other authors in relation to potassium salts. ${ }^{1218}$ It is interesting that several reported cases of patients with alleged ulceration induced by potassium were also receiving NSAID. ${ }^{12}$ It is not clear, however, why other authors $^{131419}$ reporting ulceration and perforation due to NSAID have not observed the striking diaphragm patterns described here. ${ }^{20}$ It may be relevant that the clinical diagnosis of the diaphragm lesions is difficult, requiring a high degree of suspicion and awareness. Because they are thin and do not distort the bowel wall they are not, or only rarely, shown by conventional radiological techniques. Even at surgery they are easily missed unless specifically sought. The ridged lesions with broader ulceration, however, pose no diagnostic challenge for the experienced radiologist. The status of the "mucosal diaphragms" illustrated by Thompson" in a review of the pathology of coeliac disease, is not clear. He thought that they were probably congenital and a non-steroidal aetiology was not considered. Furthermore, the lesions were in the duodenum and jejunum.

The differential diagnosis of ileal ulceration is wide. 
Davies and Brightmore ${ }^{12}$ list over 30 possibilities; Thomas and Williamson ${ }^{22}$ give 50 causes of small bowel ulceration. They are generally divided into broad groups such as congenital, mechanical, vascular, neoplastic, inflammatory and miscellaneous. Most are self-evident from the clinical history and are rare. Among the common causes, the presence of granulomas indicates Crohn's disease or tuberculosis, depending on distribution. Any hint of transmural inflammation, especially if in an aggregated pattern, again favours a diagnosis of Crohn's disease. There was no suggestion of any mural inflammation, whatever its distribution, in the cases described here. It should be emphasised, however, that because of the retrospective nature and design of this study if small bowel inflammation as a result of NSAID did indeed cause a Crohn's-like lesion, it would have been overlooked and Crohn's disease overdiagnosed.

Causes of penetrating ulcers with inflammation through to the muscularis propria need to be excluded. Penetration and perforation are documented in case reports as complications of NSAID ${ }^{10}$ but a lymphoma must be carefully considered ${ }^{23}$ as must acute fulminant Crohn's disease. Healed ischaemic strictures are usually longer than those that are drug-induced and the presence of iron-laden macrophages can be a helpful sign. Controversy surrounds the ulceration or strictures found in some patients with alleged glutenrelated enteropathy, particularly when the diagnosis has not been confidently established. ${ }^{24}$ Opinion is divided whether it is a variant of coeliac disease, ${ }^{25}$ which indicates that a lymphoma has developed, or is about to develop, whether it is an entirely separate entity of idiopathic ulcerating enteritis. ${ }^{26}$ Here, the history should help distinguish it from disease induced by NSAID. In the former groups malabsorption predominates while in the latter it is subacute obstruction.

Despite careful clinical documentation and pathology, a proportion of small intestinal ulcers and strictures remain unexplained and probably do represent primary idiopathic disease. ${ }^{27-30}$ The increasing use of colonoscopy has facilitated biopsy of the terminal ileum, and the appreciation of ileal pathology should improve. One emerging problem is the distinction of terminal ileitis in patients with reactive polyarthritis and ankylosing spondylitis ${ }^{31}$ from the effects of NSAID administered to most of these patients. None of the cases documented here involved the terminal ileum as in the cases of polyarthritis.

\section{PATHOGENESIS}

The striking pathology described in this paper requires an explanation and the patterns seen here (figs 4, 6 , and 7) permit speculation on the evolution of the lesions. In this respect the changes in the group $2 b$ (table 2) patient receiving phenylbutazone may be important (fig 10). In this case there were two short terminal ileal strictures characterised histologically by submucosal fibrosis and mucosal villous distortion. If it is accepted that these were produced by the healing of ileal ulceration induced by phenylbutazone,${ }^{14}$ then the evolution of the pathological changes might be as depicted in fig 11. The tall thin mucosal diaphragms, due to increasing fibrous obliteration of a segment of submucosa, subside through the stage of ridge or hump-like deformities to an eventual short flat stricture. The explanation for these changes must be based on the known effects of NSAID. They inhibit prostaglandin synthesis thereby changing mucosal integrity, and white cells can be detected migrating through the mucosa into the lumen. ${ }^{32}$ The mucosa may then be more vulnerable to bacteria or toxins or both..$^{3-5}$ The latter could be further potentiated by the known action of NSAID on white cell function. ${ }^{33}$ Any site of mucosal damage with focal submucosal fibrosis might change the pliability of the plicae circulares, thereby producing a permanent fold. The process could then evolve through the patterns shown in fig 11 .

It is tempting to propose that the reason that published reports are only of the flatter lesions is because the diaphragms, being difficult to detect, had been missed early on. ${ }^{1319}$ Unfortunately, there was no evidence in this study to support a purely chronological progression to the lesions depicted in fig 11 . The condition can clearly recur as one patient had two identical resections eight years apart and continued to receive NSAID. Two other patients had recurrent resections but only months apart. These were almost certainly due to a failure to appreciate the extent of the diaphragms at the time of the initial surgery. Furthermore, the length of symptoms did not correlate with the pathological patterns. For example, in case 4 (table 3) obstructive symptoms were present on and off for 18 months and even though NSAID were avoided during this time diaphragm lesions, not flat strictures, were present at the time of resection. Bjarnason et a $l^{22}$ have shown that the effects of NSAID persist for long periods after the drug has been discontinued. There is, however, some evidence for progressive stenosis over a short period but this was in a case of potassium ingestion..$^{34}$ An alternative hypothesis is that the pathology reflects the extent of damage and its rate of onset, more extensive damage and mucosal ulceration producing the flatter lesions. NSAID change intestinal motility and possibly blood flow, ${ }^{35}$ and this would affect the time the mucosa was exposed to the drug or, indeed, to other toxins.

The changes documented here are rare and a contrast to the other relatively common effects of NSAID mentioned previously. The formation of diaphragm lesions probably requires an additional 
trigger. Support for this comes from the detailed clinical analysis of some of the cases. ${ }^{36}$ In one the patient was exceeding the maximum recommended dose of NSAID three to four fold, but perhaps more relevant was that in three an attack of "gastroenteritis", with weight loss and protein-losing enteropathy, heralded the onset of the intestinal problems. The bout of severe gastroenteritis might be the additional trigger required to set the process off, with subsequent repair being faulty in the presence of NSAID.

A key question and one without an answer at present, is whether the effects of NSAID in causing these diaphragm lesions are local or systemic. Among the drugs known to cause strictures the action of potassium is believed to be one of local mucosal irritation and subsequent ischaemic damage. ${ }^{37}$ If NSAID work in a similar local manner the observation that several patients' presentations were precipitated by a severe gastroenteritic illness means that there may have been a period of disturbed intestinal motility with a decreased transit time. This exposes the ileum to high concentrations of the drug or its metabolites, as well as bacteria and their toxins, which are normally removed higher up in the gut. If, on the other hand, the mechanism is systemic it would require an abnormal and preferential ileal reaction to changed prostaglandin metabolism-this perhaps interacting across a defective mucosal barrier with luminal bacteria or toxins. It is therefore interesting that four of the patients had been prescribed piroxicam, a drug with a prolonged half-life. Even with this speculation, there is clearly a wide gap between what is known about the action of NSAID and an adequate explanation for the striking symmetrical ileal diaphragms illustrated in this study. The problem is made more poignant when it is appreciated that in case 1 (table 3) 19 such lesions were seen in the resection and the surgeon had carried out at least this number of stricturoplasties at the first laparotomy.

We thank Drs Hasleton and Gostelow for referring cases six and seven. We also thank Janet MacKenzie and medical illustration, the department of histopathology, and Lisa Rhodes, all of Northwick Park Hospital, for their help with this paper.

\section{References}

1 Kent TH, Cardelli RM, Stammler FW. Small intestinal ulcers and intestinal flora in rats given indomethacin. Am J Pathol 1969;54:237-45.

2 Fang W-F, Broughton A, Jacobsen ED. Indomethacin-induced intestinal inflammation. Am J Dig Dis 1977;22:749-60.

3 Robert A, Ansano T. Resistance of germ free rats to indomethacin-induced intestinal lesions. Prostaglandins 1977;14:331-41.

4 Satoh H, Guth PH, Grossman MI. Role of bacteria in gastric ulceration produced by indomethacin in the rat: cytoprotective action of antibodies. Gastroenterology 1983;84:483-9.

5 Whittle BJR. Temporal relationship between cyclooxygenase inhibition, as measured by prostacyclin biosynthesis, and the gastrointestinal damage induced by indomethacin in the rat. Gastroenterology 1981;80:94-8.

6 Bjarnason I, Williams P, So A, et al. Intestinal permeability and inflammation in rheumatoid arthritis: effects of non-steroidal anti-inflammatory drugs. Lancet 1984;ii:1171-4.

7 Bjarnason I, Peters TJ, Levi AJ. Intestinal permeability: clinical correlates. Dig Dis Sci 1986;4:83-92.

8 Bjarnason I, Williams P, Smethurst P, Peters TJ, Levi AJ. The effect of non-steroidal anti-inflammatory drugs and prostaglandins on the permeability of the human small intestine. Gut 1986;27:1292-7.

9 Bjarnason I, Zanelli G, Prouse P, et al. Blood and protein loss via small-intestinal inflammation induced by non-steroidal antiinflammatory drugs. Lancet 1987;ii:711-4.

10 Langman MJS, Morgan L. Worrall A. Use of anti-inflammatory drugs by patients admitted with small or large bowel perforations and haemorrhage. Br Med J 1985;290:347-9.

11 Sturge HF, Krone CL. Ulceration and stricture of the jejunum in a patient on long-term indomethacin therapy. Am J Gastroenterol 1973;59:162-9.

12 Davies DR. Brightmore T. Idiopathic and drug-induced ulceration of the small intestine. Br J Surg 1970;57:134-9.

13 Saverymuttu SH. Thomas A, Grundy A, Maxwell JD. Ileal stricturing after long-term indomethacin treatment. Postgrad Med J 1986:62:967-8.

14 Neoptolemos JP. Locke TJ. Recurrent small bowel obstruction associated with phenylbutazone. Br J Surg 1983;70:244-5.

15 Day TK. Intestinal perforation associated with osmotic slow release indomethacin capsules. $\mathrm{Br}$ Med J 1983;287:167-2.

16 Price AB, Morson BC. Inflammatory Bowel Disease. The surgical pathology of Crohn's disease and ulcerative colitis. Hum Pathol 1975:6:7-29.

17 Morgenstern L, Freilich M, Panish JF. The circumferential smallbowel ulcer JAMA 1965;191:101-4.

18 Lawrason FD, Alpert E. Moht FI, McMahon FG. Ulcerativeobstructive lesions of the small intestine. JAMA 1965;191: 105-8.

19 Madhok R, MacKenzie JA, Lee FD, Bruckner FE, Terry TR, Sturrock RD. Small bowel ulceration in patients receiving non-steroidal anti-inflammatory drugs for rheumatoid arthritis. $Q J$ Med 1986;255:53-8.

20 Lang J, Bjarnason I, Levi AJ, Price AB. Pathology of iatrogenic ileal strictures caused by non-steroidal anti-inflammatory drugs. J Pathol 1986;149:221 A.

21 Thompson H. Pathology of Coeliac Disease. In: Morson BC, ed. Pathology of the gastro-intestinal tract. Berlin: Springer-Verlag, 1976:49-75.

22 Thomas WEG, Williamson RCN. Enteric ulceration and its complications. World J Surg 1985;9:876-86.

23 Isaacson P, Wright DM. Malignant histiocytosis of the intestine: its relationship to malabsorption and ulcerative jejunitis. Hum Pathol 1978;9:661-77.

24 Robertson DAF, Dixon MF, Scott BB, Simpson FG, Losowsky MS. Small intestinal ulceration: diagnostic difficulties in relation to coeliac disease. Gut 1983;24:565-74.

25 Bayless TM, Kapelowitz RF, Shelley WM, Ballinger WF, Hendrix TR. Intestinal ulceration: a complication of coeliac disease. N Engl J Med 1967;276:996-1002.

26 Mills PR, Brown IL. Watkinson G. Idiopathic chronic ulcerative enteritis. $Q J$ Med 1980;49:133-49.

27 Thomas WEG, Williamson RCN. Nonspecific small bowel ulceration. Postgrad Med J 1985;61:587-91.

28 Reid J, Gilmour HM, Holt S. Primary non-specific ulcer of the small intestine. $J R$ Coll Surg Edinb 1982;27:228-32.

29 Ballantyne KC, Morris DC, Hawkey CJ. Hardcastle JD. Haemorrhage from idiopathic annular ulcers of the small intestine. Ann R Coll Surg Engl 1986;68:168-9. 
30 Boydstun JS, Gaffey TA, Bartholomew LG. Clinico-pathologic study of non-specific ulcers of the small intestine. Dig Dis Sci 1981;26:911-6.

31 Cuvelier C, Barbatis C, Mielants H, De Vos M, Roels H, Veys E. Histopathology of intestinal inflammation related to reactive arthritis. Gut 1987;28:394-401.

32 Bjarnason I, Zanelli G, Smith T, et al. Nonsteroidal antiinflammatory drug-induced intestinal inflammation in humans. Gastroenterology 1987;93:480-9.

33 Warne PJ, West GB. Inhibition of leucocyte migration by salicylates and indomethacin. J Pharm Pharmacol 1978;30:7835.

34 Tresaderm J, Rickwood AMK, Spitz L. Multiple small bowel strictures in a child and accidental potassium chloride ingestion. Br Med J 1977;ii:1124-5.
35 Nowak J, Wennmalm A. Influence of indomethacin and of prostaglandin E1 on total and regional blood flow in man. Acta Physiol Scand 1978;102:484-9.

36 Bjarnason I, Price AB, Zanelli G, et al. Clinico-pathological features of non-steroidal anti-inflammatory drug induced small intestinal strictures. Gastroenterology 1988:(in press).

37 Boley SJ, Schultz L, Krieger H, Schwartz S, Elguezabel A, Allen AC. Experimental evaluation of thiazides and potassium as a cause of small bowel ulcer. JAMA 1965;192:763-8.

Requests for reprints to: Dr A B Price, Department of Pathology, Northwick Park Hospital and Clinical Research Centre, Watford Road, Harrow, Middlesex HAl 3UJ, England.
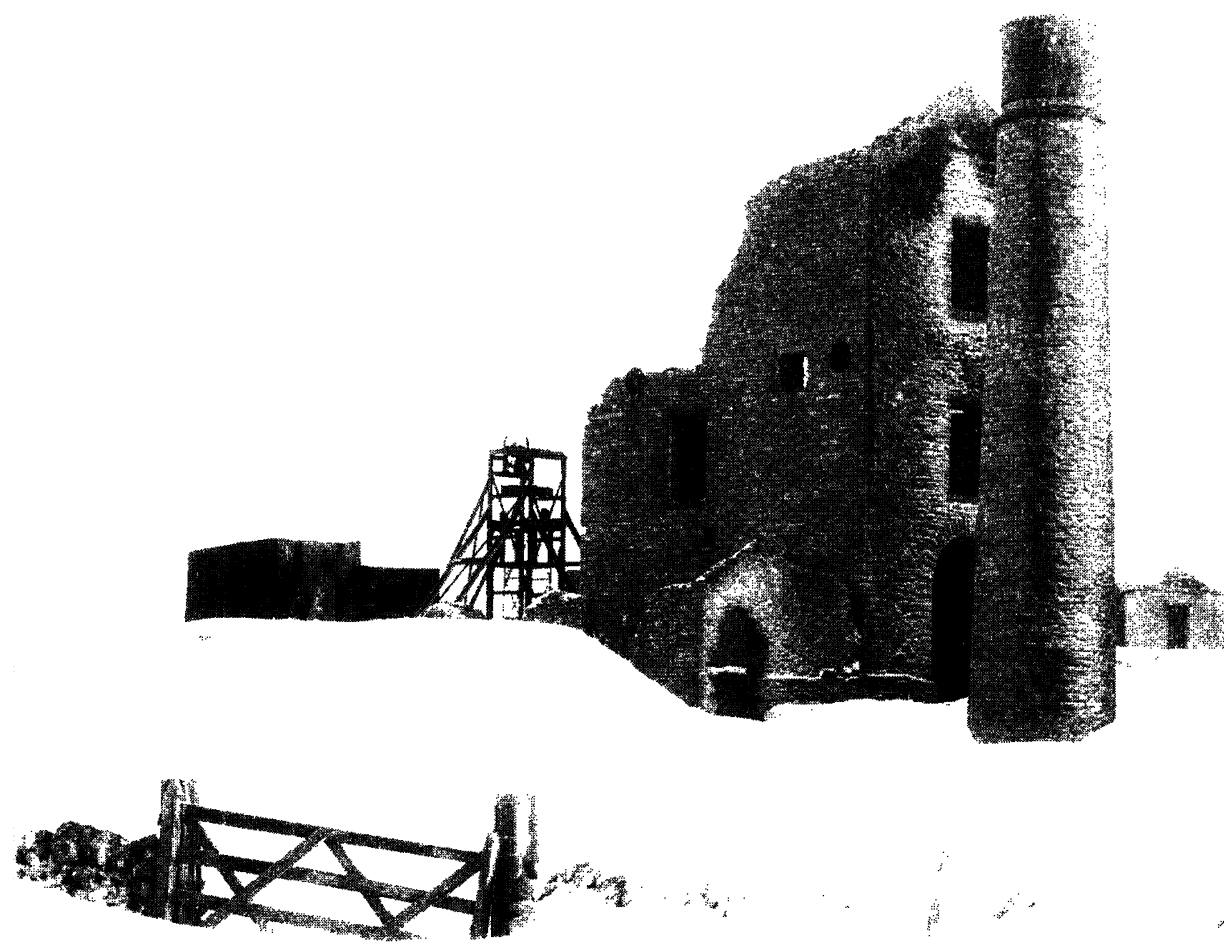

Magpie Mine, Sheldon

W R TIMPERLEY

Many pathologists are also photographers. To lighten the occasional space at the end of articles the Journal is anxious to acknowledge this, and is pleased to publish various examples of their work as above. Please submit unmounted black and white prints, $14 \mathrm{~cm} \times 12 \mathrm{~cm}$, with an appropriate legend. Those accepted will be attributed. Within the bounds of good taste, subject matter is immaterial-quality is everything. 